\title{
Modified attia approach for enormous pleomorphic adenoma of para-pharyngeal space with all-embracing chondroid calcification $-A$ rare case report
}

\section{Vishal Bansal*}

Professor and Head, Department of OMFS, Subharti Dental College, India

\section{Introduction}

Parapharyngeal space (PPS) is one of potential space of head and neck region and due to its hidden anatomical location, pathologies arising in this space are late to diagnose. This inverted pyramidal space was termed previously as pterygomaxillary space, lateral pharyngeal space and pharyngio-maxillary space. Parapharyngeal space is the current term that has come to stay because of indistinct image of its location. Anatomically parapharyngeal space divides into two spaces i.e. pre-styloid and post styloid. This space contains highly vital structure like carotid sheath, cranial nerves IX, X, XI, and XII, sympathetic trunk, superior cervical ganglion of trunk, maxillary artery, ascending pharyngeal artery and deep part of parotid gland. This space is also full of loose connective tissue and minor salivary glands and lymph nodes. Pathologies are more likely to happen from above mentioned vital structures namely neurogenic tumor (schwanoma, neurofibroma, glomus vagale tumors) and benign or malignant salivary gland tumors. PPS tumors are very rare and accounts for $0.5 \%$ tumors of head and neck region. Most of these tumors i.e. $72 \%$ are benign and $40-50 \%$ originates from the salivary glands [1]. Pleomorphic adenoma in PPS can develop de novo probably from displaced or aberrant salivary gland tissue within the lymph node, minor salivary gland or deep lobe of parotid gland that can extend through stylomandibular tunnel through PPS $[2,3]$. Due to close proximity to vital and vascular structures and not easy accessibility leads to high difficulty index for maxillofacial surgeons in management of PPS tumors.

\section{Case report}

\section{Clinical presentation}

A 23 year old female presented with gradual progressive painless swelling in throat and neck region since 18 months. Swelling was associated with difficulty in deglutition and reduced mouth opening since 1 year. Patient had multiple consultations for these symptoms which was misdiagnosed as an impacted tooth with peritonsillar abscess and subsequently given antibiotics with extraction of left upper and lower $3^{\text {rd }}$ molar. On inspection, a non-ulcerated large mass occupying left lateral pharyngeal wall not crossing the midline was seen intra-orally (Figure 1). There was diffuse firm fullness also noticed in submandibular trigone extraorally. On palpation there was a smooth, firm, rubbery tender bulge over soft palate and left pharyngeal wall with no pulsations. Swelling was bimanually palpable and ballotable in left submandibular region. Classical sign of ballotement was negative but movements were palpable in submandibular region. No significant lymphadenopathy and involvement of any of the cranial nerves were present; hoarseness of voice was absent. Based on history and clinical examination, probable clinical diagnosis of soft tissue chondroma, schwanoma or benign salivary gland tumor was established.

\section{Radiographic findings}

An OPG revealed flocculent snowflakes like radio-opaque mass superimposed on left side of ramus of mandible with no sign of resorption of mandible (Figure 2). Differential diagnosis of chondroma, chondrosarcoma, progressive myositis ossificans, cemento -ossifing fibroma, pleomorphic adenoma with calcification in PPS were considered. With above mentioned clinical and radiographic diagnosis patient was advised contrast MRI scan which showed large, well circumscribed, encapsulated soft tissue lesion measuring approximately $(6.0 \times 5.5 \times$ $5.2 \mathrm{~cm}$ ) epicentered in left parapharyngeal space extending cranially into infratemporal fossa with close proximity to middle cranial fossa and displacement, distortion of nasopharyngeal, oropharyngeal air space was also observed. The fat planes between the mass with deep lobe of parotid gland on T1 images were fairly preserved (Figure 3). On contrast study predominantly heterogeneous shaggy peripheral

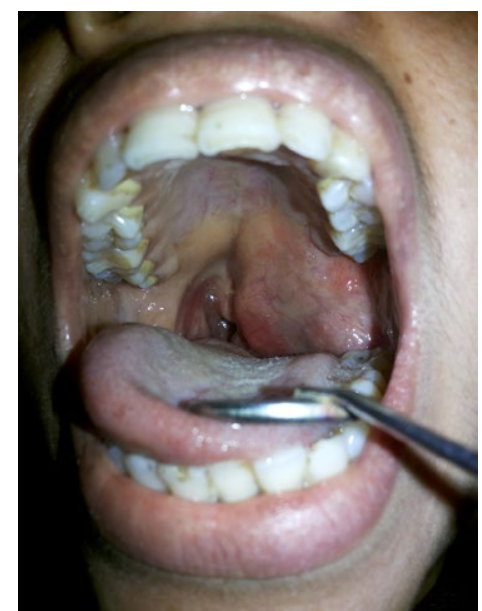

Figure 1. Intraoral large mass occupying the left oropharyngeal region.

Correspondence to: Vishal Bansal, Department of OMFS, Subharti Dental College, India, E-mail: dr.avibansal@gmail.com

Received: July 02, 2015; Accepted: October 09, 2015; Published: October 12 , 2015 


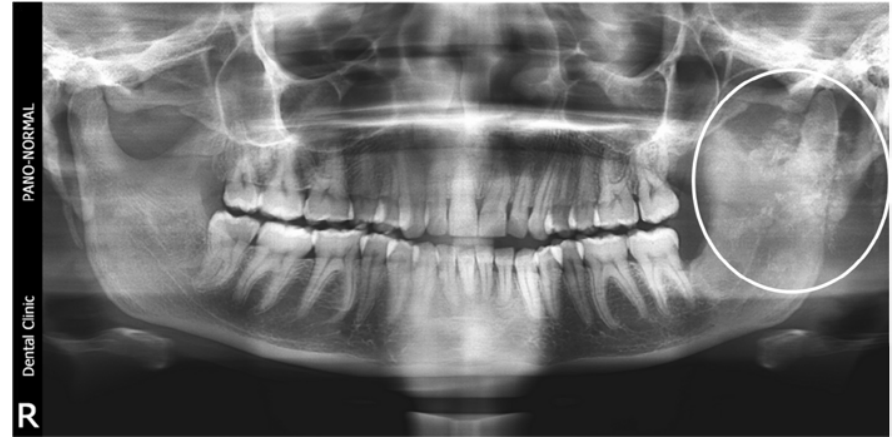

Figure 2. Flocculent snowflakes like radio-opaque mass superimposed on left side of ramus of mandible in OPG.

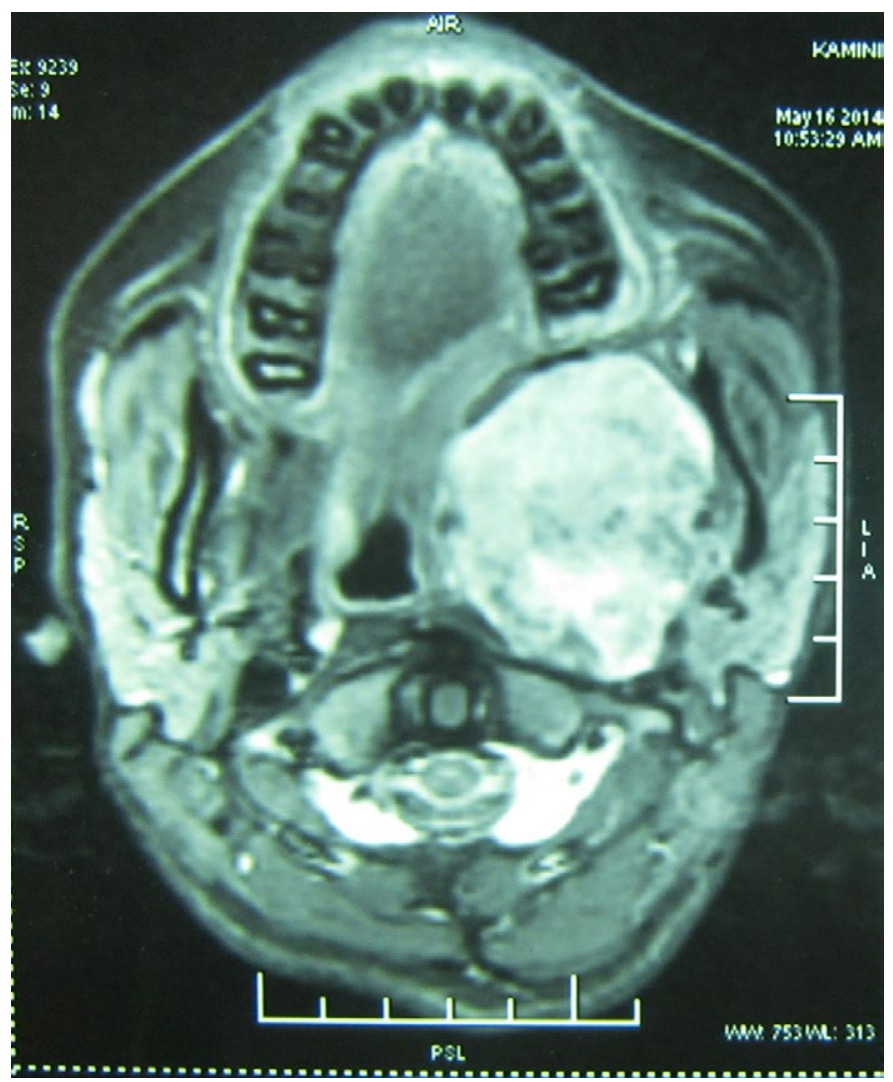

Figure 3. MRI - Axial view.

and multiple patchy area of blooming was suggestive of intra-tumoral calcification and Carotid sheath was displaced postero-laterally by mass. MRI images reported that mass maybe soft tissue fibro-osseous lesion, extraosseous osteosarcoma, chondroma, chondrosarcoma or benign minor salivary gland tumor with large amount of calcification.

\section{Surgical management}

All above mentioned provisional diagnosis were in favor of non vascular lesion. FNAC findings were inconclusive so an incisional biopsy was performed by giving incision over the ascending border of ramus. On exposure of medial aspect, white rubbery firm to hard mass was found which had to be incised with No-11 blade for purpose of histopathological examination. The incisional biopsy revealed predominant chondroid tissue, osseous tissue with bone marrow like structure and a small island of epithelial component proliferating in the form of ducts, which was suggestive of pleomorphic adenoma.

On the basis of histopathological findings and well defined encapsulated PA extending from PPS to infratemporal fossa and a need of good access, it was decided to excise the tumour under general anesthesia via modified Attia double osteotomy approach without lip splitting submandibular incision under an aseptic protocol. After marking of submandibular incision in neck crease, $2 \mathrm{~cm}$ below the lower border of mandible till midline, skin/platysmal flap preserving the marginal branch of facial nerve slightly more dissection was carried out as compared to conventional submandibular approach. After ligation of facial vein, artery and stripping of lower two third masseter muscle, lateral subperiosteal dissection was performed from midline to left side of condyle and ascending border of ramus. With the aid of lingual crevicular incision starting from mandibular central incisor continued till last molar and up to anterior border of ramus; full thickness lingual mucoperiosteal flap was elevated from lingual aspect of mandible. Sphenomandibular ligament, medial pterygoid attachment from medial ramus and stylomandibular ligament from posterior border of mandible in angle area were dissected. Before carrying out osteotomies intermaxillary fixation was done to secure the occlusion of the patient. In double osteotomy one Step osteotomy anterior to mental foramen and another horizontal above the antilingula was marked with 701 bur (Figure 4). After adapting the titanium mini plates fixed with screws and removed from planned cut, osteotomy was carried out .This allowed to swing the mandible in superior and lateral direction which led to direct and unparalleled access from skull base to hyoid bone. Blunt dissection was further carried out to enucleate the tumor by preventing the major vessels (Figure 5). Minor ooze was noticed in operated area which was managed with pressure pack. To stabilize the mandible, fixation of osteotomized segment with two mini plates on each side was carried out (Figure 6). Suturing of lingual crevicular incision with interrupted figure of 8 with buccal papilla, E/O layer closure after securing the drain tube and pressure completed the surgical procedure. Pressure dressing and drain tube were removed after 72 hours and patient was advised soft, liquid diet for 14 days. Macroscopically specimen was white in color, lobulated, hard and gritty in consistency (Figure 7). Excised specimen was sent for radiographic (Figure 8) and histopathological examination. Patient recovered uneventfully with gradual improvement in mouth opening and rapid recovery in swallowing difficulty (Figure 9).

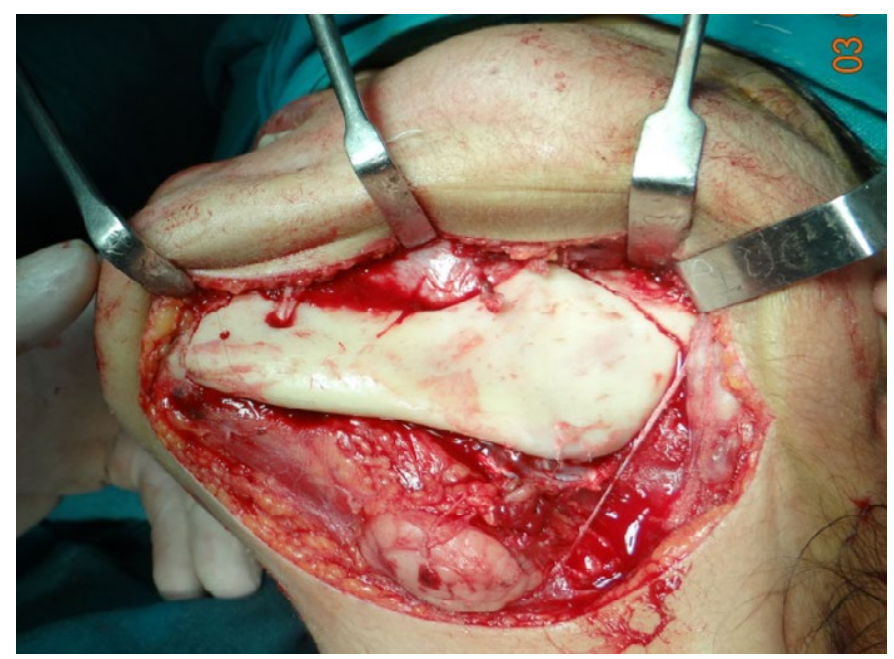

Figure 4. Planned double osteotomy. 


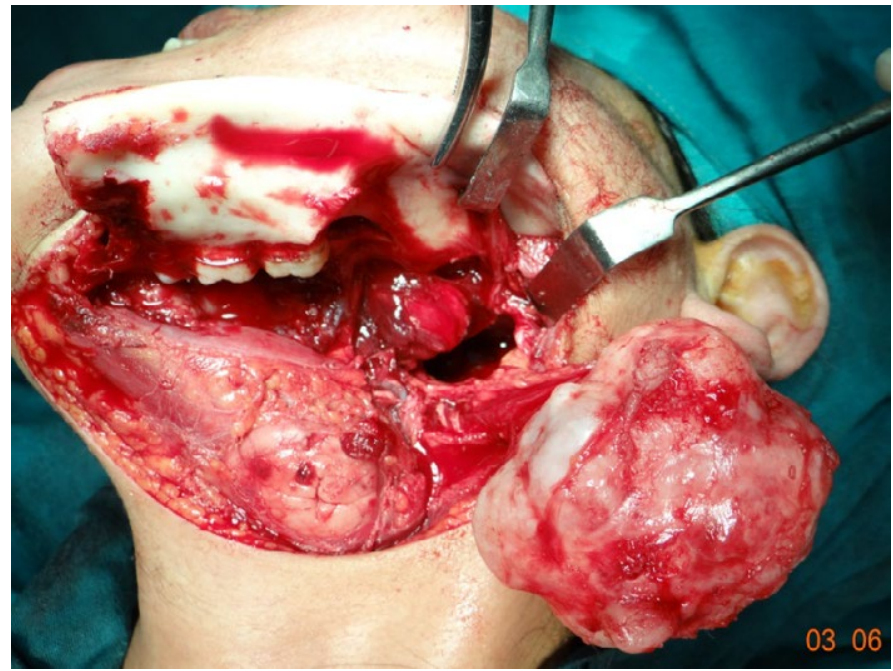

Figure 5. Superior and lateral swing of the mandible and giant tumor mass.

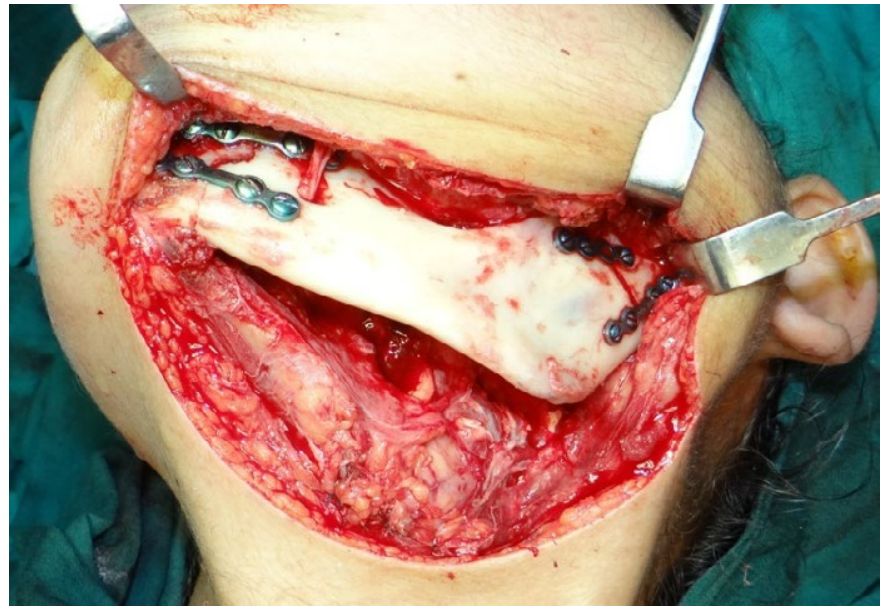

Figure 6. Stabilization of mandible with Titanium miniplate osteosynthesis.

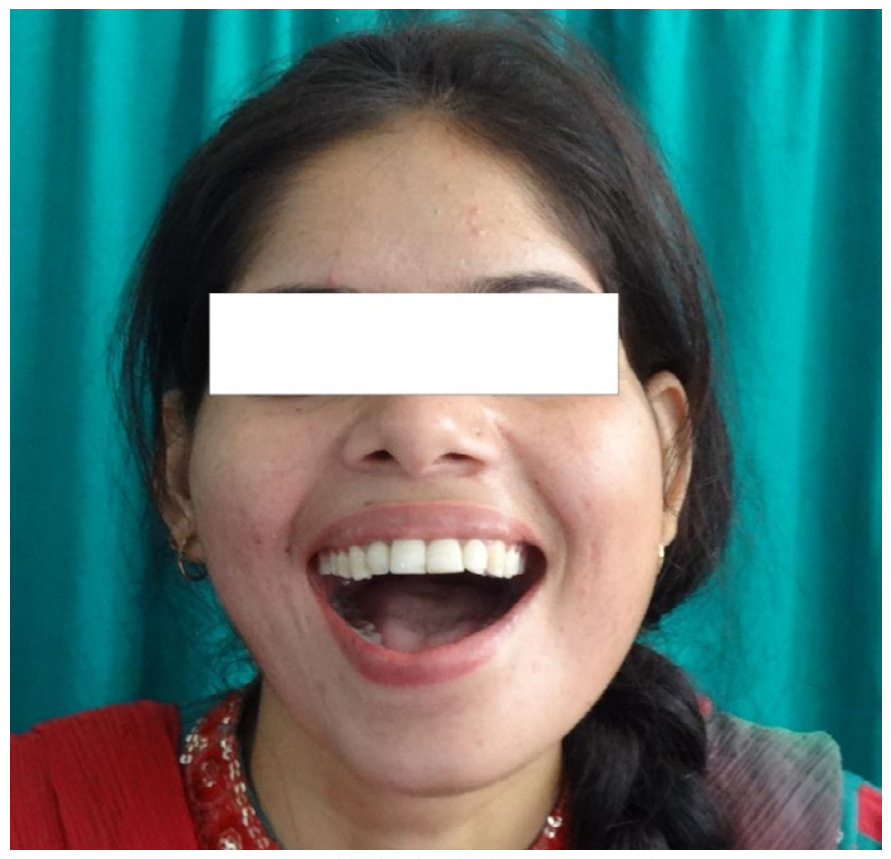

Figure 7. White hard and gritty mass on cutting.

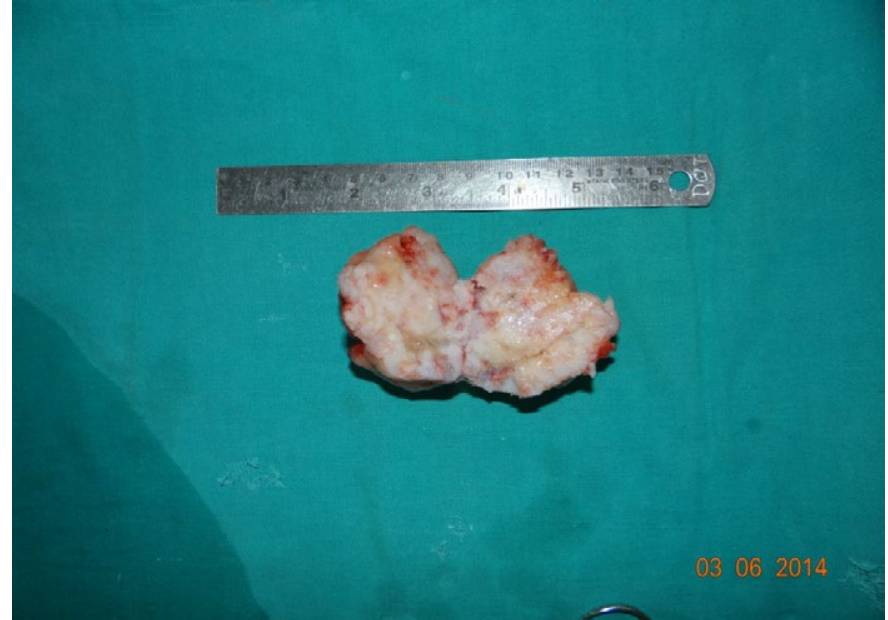

Figure 8. Radiograph of specimen showing huge amount of calcification.

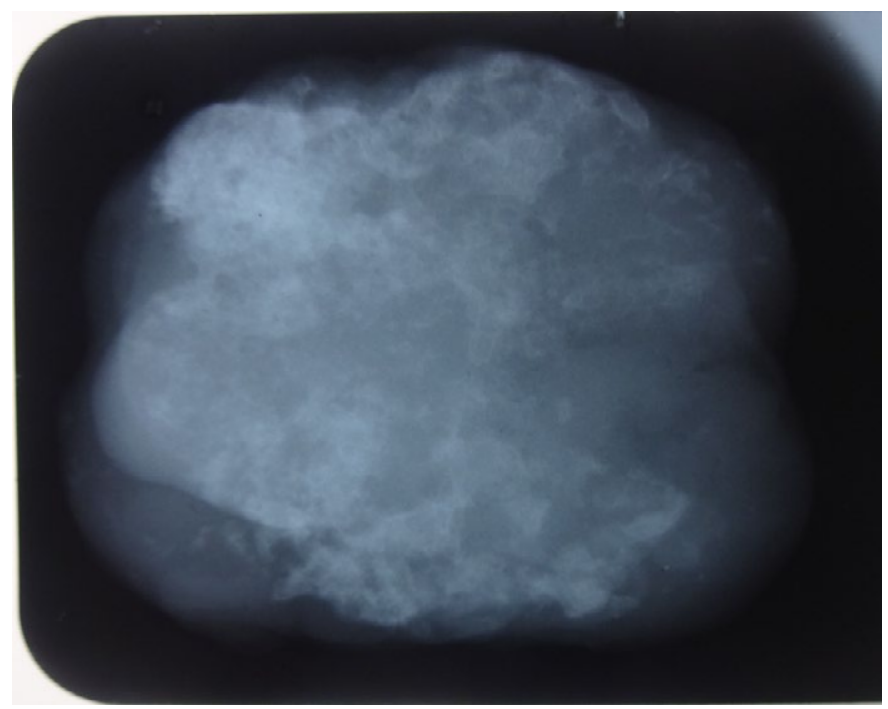

Figure 9. Two months post-operative.

\section{Histopathological findings}

Hematoxylin and eosin stained section showed the presence of myoepithelial cells, that appeared to be spindle shaped and hyperchromatic, proliferating around the ducts filled with eosinophilic material. A small foci of squamous cells too was seen near the capsule as a set of glandular epithelium. Occasional areas showed myxoid degeneration. The tumor largely demonstrated extensive chondroid tissue formation which was confirmed further by alcian blue staining which showed the presence of chondrocytes in their lacunae. Few areas showed ossification and vascular stroma was evident at the areas showing chondroid tissue merging with the bone representative of endochondral ossification. Thus, on ground of admixture of chondroid, osseous and myxoid mesenchymal component and epithelial component, the tumor was diagnosed as pleomorphic adenoma with extensive chondroid metaplasia undergoing ossification (Figure 10).

\section{Discussion}

Pleomorphic adenoma commonly occurs in $3^{\text {rd }}$ to $6^{\text {th }}$ decade with slight more predilections in females and accounts for only $10 \%$ in 


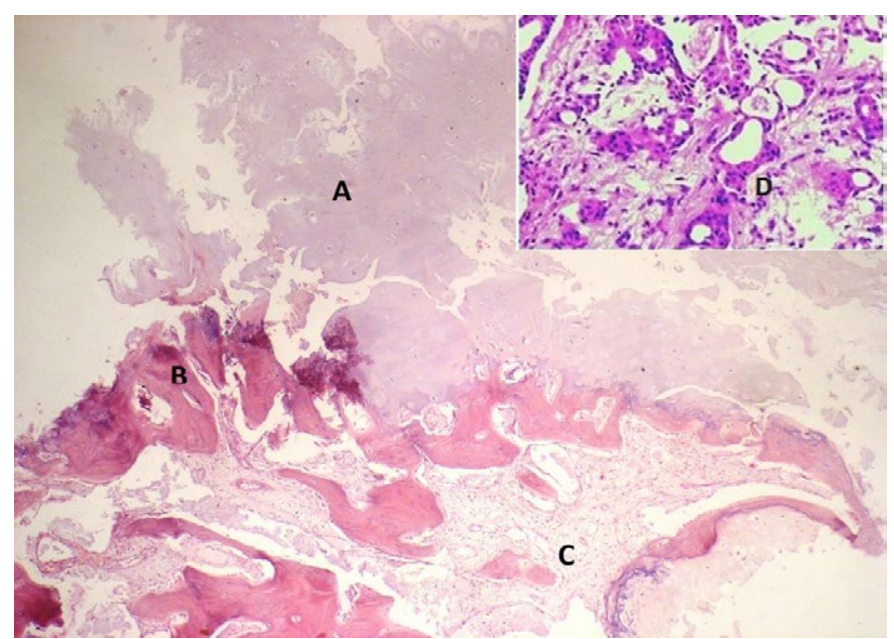

Figure 10. Microphotographs- [HandE (4 X)] showing A- extensive chondroid tissue, Bosseous tissue and C- fibro-cellular connective tissue showing numerous blood capillaries and inset $[\mathrm{HandE}(10 \mathrm{X})]$ showing proliferating myoepithelial cells around the ducts.

minor salivary glands $[4,5]$. Histopathologically, essential components of PA are encapsulation, myoepithelial cells and mesenchymal or stromal elements. Mesenchymal elements are responsible for producing mucoid/myxoid, cartilaginous and hyalinized material [6]. According to Harrison [7] calcification in PA is generally found in lumen and epithelial cells. The small collections of crystals in the lumen which are often associated with membranous cellular debris, forms a large calcified mass by fusion. More often osseous tissue observed in the area of chondroid tissue due to endochondral ossification. Vascular invasion is the key factor for endochondral ossification in PA, but usually no vascular invasion is seen in chondroid areas. In our case many micro vessels were found associated with chondroid and osseous tissue thus confirming endochondral ossification in pleomorhic adenoma [8]. Focal or partial calcification is occasionally associated with PA, but enormous cartilaginous and calcification was seen in our case which helped in complete enucleation of tumor like a rubber ball. In English literature we came across only one case that has been reported as PA of PPS with extensive ossified and calcified degeneration [9]. Immunohisto chemistry may be supportive in delineating the different cell types and components by CK, S-100,GFAP, Vimentin, Actin and calponin. In our case diagnosis of PA with huge amount of chondroid calcification was made through microscopic identification and due to unavailability of all above mentioned markers IHC was not performed in our center. PA is a slow growing tumor, reason for PPS deep seated PA produce symptoms once they become large mass. Sign and symptoms of PPS tumour depends on the tissue of origin and affect of the mass of surrounding structure like conductive hearing loss due to middle ear effusion if Eustachian tube is blocked, paralysis of ipsilateral vocal cord due to involvement of vagus nerve, ipsilateral paralysis of tongue due to involvement of hypoglossal nerve, Horner's syndrome due to involvement of cervical sympathetic chain, Vernet's syndrome due to paralysis of cranial nerve in the jugular foramen and rhinolalia clausa i.e. nasal quality of speech due to large oropharyngeal mass which were not present in our case. Trismus and difficulty in deglutition were the main symptoms in our case. Restricted mouth opening may be due to irritation of pterygoid muscle or due to mechanical impediment of the mandible and dysphagia due to large mass obstructing or spasm of the muscles of deglutition. MRI plays an important role in diagnosing soft tissue tumors of PPS, not only to rule out the extension of the lesion but also to find out proximity of the vital structures like carotid sheath to the pathology. Another advantage of MRI is to know the shape e.g. dumble shape in case of tumor arising from deep lobe of parotid gland and if fatty layer present between the deep lobe of the parotid gland and pathological mass suggestive of tumor is arising from one of the contents of PPS. Long term follow up is mandatory in younger patients to ensure diseases free period although PA arising from minor salivary glands has very low recurrence of $3.4 \%$ in 5years [10]. Various surgical techniques have been discussed in literature to access this potential space like trans parotid, trans cervical, cervical trans pharyngeal, midline mandibulotomy anterolateral, lateral osteotomies of mandible [11]. E.L. Attia in 1984 first described and published in the journal of Head and Neck surgery "A new external approach to the pterygomaxillary fossa and parapharyngeal space" by double osteotomy [12]. Attia described in his original technique role of tracheostomy at starting or completion of surgery, lower lip split incision, lingual sulcus incision on floor of mouth, straight vertical osteotomy anterior to the mental foramen and suggestion with wire osteosynthesis which necessitate a course of maxillomandibular fixation. Idea of using tracheostomy may be concern of detachment of geniohyoid and genioglossus muscle or extensive malignancy cases, seems to be not necessary in benign cases if anterior osteotomy is kept lateral to genial tubercle. According to Carlson et al. [13], lower lip splitting is unnecessary, cosmetically unfavorable and the use of rigid fixation to eliminate MMF, same modification was applied by the author which resulted acceptable cosmetic and functional outcome. Instead of lingual sulcular incision on floor of mouth modification was reported as lingual crevicular incision [14]. Same modification was performed in our technique and the previous experiences showed that there is no injury to the Wharton's duct, lingual nerve and nil chances of oro-cutaneous fistula. Keeping the step osteotomy anterior to the mental foramen between the canine and $1^{\text {st }}$ premolar maintains the chin contour and prevents the malunion and injury to the mental foramen. It appears that with all above modifications we can produce acceptable functional and early esthetic outcome though long term follow up is to be seen.

\section{Conclusion}

Tumors of para-pharyngeal space although mostly benign in nature present a challenge to the surgeon due to its limited access. Although various techniques to approach parapharyngeal space are mentioned in literature with its pros and cons. Modification in Attia approach seems to be a superior technique in terms of accessibility, functional and cosmetic results.

\section{References}

1. Khafif A, Segev Y, Kaplan DM, Gil Z, Fliss DM (2005) Surgical management of parapharyngeal space tumors: a 10-year review. Otolaryngol Head Neck Surg 132: 401-406. [Crossref]

2. Rodríguez-Ciurana J, Rodado C, Sáez M, Bassas C (2000) Giant parotid pleomorphic adenoma involving the parapharyngeal space: report of a case. J Oral Maxillofac Surg 58: 1184-1187. [Crossref]

3. Varghese BT, Sebastian P, Abraham EK, Mathews A (2003) Pleomorphic adenoma of minor salivary gland in the parapharyngeal space. World J Surg Oncol 1: 2. [Crossref]

4. Eveson JW, Cawson RA (1985) Salivary gland tumours. A review of 2410 cases with particular reference to histological types, site, age and sex distribution. $J$ Pathol 146 : 51-58. [Crossref]

5. Waldron CA, el-Mofty SK, Gnepp DR (1988) Tumors of the intraoral minor salivary glands: a demographic and histologic study of 426 cases. Oral Surg Oral Med Oral Pathol 66: 323-333. [Crossref] 

report

6. Barnes L, Eveson JW, Riechart P et al. (2005) eds. World Health Organization Classification of Tumors: Pathology and Genetics of Head and Neck Tumours. Lyon, France: IARC Press: 254-258.

7. Harrison JD (1991) Ultrastructural observation of calcification in a pleomorphic adenoma of the parotid gland. Ultrastruct Pathol 15: 185-188. [Crossref]

8. Kusafuka K, Yamaguchi A, Kayano T, Takemura T (1998) Immunohistochemical localization of fibroblast growth factors (FGFs) and FGF receptor-1 in human normal salivary glands and pleomorphic adenomas. J Oral Pathol Med 27: 287-292. [Crossref]

9. Shi H, Wang P, Wang S, Yu Q (2008) Pleomorphic adenoma with extensive ossified and calcified degeneration: unusual CT findings in one case. AJNR Am J Neuroradiol 29: 737-738. [Crossref]

10. Spiro RH (1986) Salivary neoplasms: overview of a 35-year experience with 2,807 patients. Head Neck Surg 8: 177-184. [Crossref]
11. Hughes KV 3rd, Olsen KD, McCaffrey TV (1995) Parapharyngeal space neoplasms Head Neck 17: 124-130.

12. Attia EL, Bentley KC, Head T, Mulder D (1984) A new external approach to the pterygomaxillary fossa and parapharyngeal space. Head Neck Surg 6: 884-891. [Crossref]

13. Carlson ER, Schimmele SR (1998) Atlas of the oral and maxillofacial surgery clinics of North America. 6: 84-88.

14. Biedlingmaier JF, Ord R (1994) Modified double mandibular osteotomy for tumors of the parapharyngeal space. J Oral Maxillofac Surg 52: 348-352. [Crossref]

Copyright: $\odot 2015$ Bansal V. This is an open-access article distributed under the terms of the Creative Commons Attribution License, which permits unrestricted use, distribution, and reproduction in any medium, provided the original author and source are credited. 